\title{
Anomalous origin of the right coronary artery from the pulmonary trunk
}

\author{
Maksim Zagura, ${ }^{1}$ Sa Tran, $^{2}$ Sujal Desai ${ }^{2}$
}

${ }^{1}$ Department of Radiology Tartu University Hospital, Tartu, Tartumaa, Estonia

'Department of Radiology, King's College Hospital, London, UK

\section{Correspondence to} Dr Maksim Zagura, maksim.zagura@kliinikum.ee

Accepted 23 March 2016

\section{DESCRIPTION}

A 55-year-old woman presented to cardiology clinic with chest heaviness, which worsened with walking and deep inspiration. The sensation of chest heaviness had lasted for about a year. Cardiac and chest auscultation were unremarkable. The patient's cardiovascular risk factors included treated hypertension. There was no family history of coronary artery disease. The patient's ECG demonstrated sinus bradycardia with no ST-segment changes and normal QRS morphology. Transthoracic echocardiography showed normal left ventricular systolic function with mild left ventricular hypertrophy and no valvular abnormality. Furthermore, stress echocardiography was negative for ischaemia at $80 \%$ of maximum heart rate. Subsequently, the patient was referred to CT cardiac angiography. The patient's calcium score was 0 . Contrast angiography demonstrated that the right coronary artery (RCA) had originated from the pulmonary trunk (figures 1 and $2 \mathrm{~A}$ ). The origin of the left coronary artery was normal (figure $2 \mathrm{~B}$ ). Tortuous collaterals from the LAD to the inferior wall of the heart were noted (figure 2B). In neither the left main stem, left anterior descending artery, circumflex artery nor RCA was luminal stenosis identified. Furthermore, exercise stress echocardiography was conducted, which was negative for ischaemia. The patient's management was discussed at a joint cardiology and cardiothoracic meeting

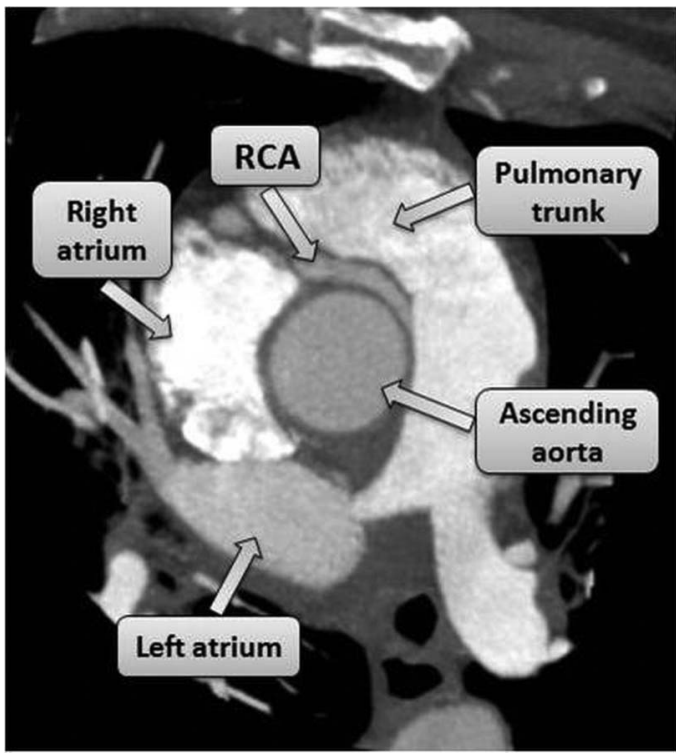

Figure 1 Maximum intensity projection. The right coronary artery originates from the pulmonary trunk. $\mathrm{RCA}$, right coronary artery. and it was decided to continue conservative treatment. However, further follow-up was advised.

Coronary artery anomalies are present in up to $1 \%$ of the population and are classified into anomalies of origin, anomalies of the course and anomalies of termination. ${ }^{1}$ Ectopic origin of a coronary artery from the pulmonary trunk is part of a group of rare anomalies that carry a high risk of myocardial infarction and sudden death. Increased risk of
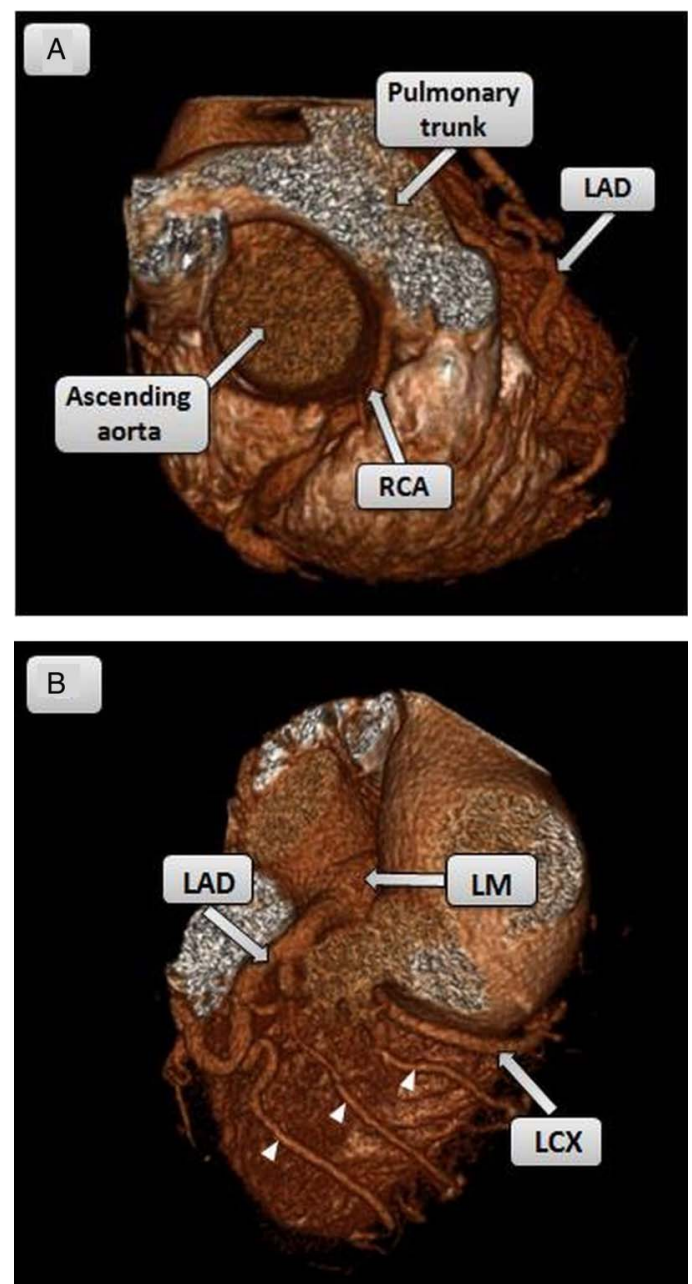

Figure 2 Three-dimensional volume rendering images. (A) The right coronary artery arises from the pulmonary trunk and passes to the right and inferiorly in the right atrioventricular groove. (B) There is a normal origin of the left coronary artery. Collateral vessels from LAD to inferior wall of the left ventricle are noted (white arrowheads). In neither the left nor right coronary artery, nor in their major branches, was luminal stenosis detected. LAD, left anterior descending artery; LCX, left circumflex artery; LM, left main stem; RCA, right coronary artery. 
sudden death may be associated with the intra-arterial course of the ectopic artery, narrowing of the coronary ostium, coronary artery spasm or arrhythmia secondary to minor ischaemic events. ${ }^{2}$ Anomalous origin of the left coronary artery from the pulmonary artery (ALCAPA) is present in the most common form, as in the embryo, the left coronary bud is located closer to the pulmonary artery sinus than the right coronary bud. ${ }^{3} 4$ The onset of symptoms usually occurs about 8 weeks after birth, when the pulmonary artery pressure decreases, which in turn reduces the flow in the left coronary artery. ${ }^{4}$ Patients with ALCAPA usually present with left ventricular dysfunction, mitral regurgitation, myocardial infarction or congestive heart failure. ${ }^{4}$ The most important differential diagnosis in this age group is dilated cardiomyopathy. Surgical correction of ALCAPA includes transfer of the ectopic coronary artery into the aorta or coronary artery bypass grafting with closure of the ectopic artery. ${ }^{5}$

ARCAPA occurs more rarely than ALCAPA, having an estimated prevalence of two cases per 100000 population. ${ }^{3}$ The clinical picture of ARCAPA is highly variable. Patients with ARCAPA may present with chest pain, congestive heart failure, acute myocardial infarction, palpitations or cyanosis. ${ }^{3}$ Less common presentations of ARCAPA include respiratory distress and cardiac arrest. ${ }^{6}$ At physical examination, systolic or diastolic murmur may be detected, whereas ECG changes are nonspecific. Up to $50 \%$ of patients with ARCAPA have concomitant cardiac anomalies, which include tetralogy of Fallot, ventricular or atrial septal defect, double outlet right ventricle, coarctation of aorta, patent ductus arteriosus or pulmonary stenosis. ${ }^{3}$ Moreover, the ectopic RCA is often thin-walled and dilated, which increases the risk of rupture. ${ }^{3}$ The patients' prognosis depends on the development of collateral circulation between the ectopic and normal coronary arteries. ${ }^{3}$ In our patient, multiple collateral vessels between the left and the RCA were seen at CT angiography. Thus, extensive collateralisation to the vascular territory of RCA might explain why stress echocardiography was negative for ischaemia.

Identification of coronary anomalies is frequently difficult with echocardiography but it may be important in detection of other concomitant congenital cardiac pathologies. ${ }^{7}$ ECG-gated cardiac CT angiography is the imaging modality of first choice for the assessment of the origin and course of the coronary arteries, for the preoperative planning of coronary reimplantation and for the postoperative follow-up. ${ }^{7}$ The major advantages of cardiac MRI include lack of ionising radiation, high temporal resolution and the ability to assess myocardial function and viability, which are important in surgical planning. Stress perfusion MRI has high sensitivity for detection of myocardial ischaemia. ${ }^{7}$ Conventional angiography is nowadays rarely performed for diagnostic purposes, however, it is indicated when endovascular treatment is necessary.

In conclusion, ARCAPA is a rare but potentially lifethreatening congenital anomaly; therefore, regular cardiology follow-up is required. The management of patients with ARCAPA depends on the clinical picture, the presence of associated congenital anomalies, left ventricular function and the evidence of myocardial ischaemia. ${ }^{1}$ Reimplantation of the RCA to the aorta is regarded as the treatment of choice, and reduces the risk of myocardial infarction and malignant ventricular arrhythmias in patients with ARCAPA. ${ }^{5}$

\section{Learning points}

- Anomalous origin of the RCA from the main pulmonary artery (ARCAPA) is a rare congenital disorder accounting for $0.12 \%$ of all coronary anomalies.

- ARCAPA has been associated with additional cardiovascular anomalies including atrial or ventricular septal defect, tetralogy of Fallot and coarctation of the aorta.

- Surgical treatment of the ARCAPA should be performed before the development of left ventricular dysfunction.

Contributors MZ collected the data and prepared the manuscript. ST participated in data analysis and preparation of the manuscript. SD participated in preparation and revision of the manuscript.

Competing interests None declared.

\section{Patient consent Obtained.}

Provenance and peer review Not commissioned; externally peer reviewed.

\section{REFERENCES}

1 Angelini P, Velasco JA, Flamm S. Coronary anomalies: incidence, pathophysiology, and clinical relevance. Circulation 2002;105:2449-54.

2 Hirono $\mathrm{K}$, Hata $\mathrm{Y}$, Miyao $\mathrm{N}$, et al. Anomalous origin of the right coronary artery evaluated with multidetector computed tomography and its clinical relevance. J Cardiol 2016 (in press).

3 Williams IA, Gersony WM, Hellenbrand WE. Anomalous right coronary artery arising from the pulmonary artery: a report of 7 cases and a review of the literature. $\mathrm{Am}$ Heart J 2006;152:9-17.

4 Pena E, Nguyen ET, Merchant N, et al. ALCAPA syndrome: not just a pediatric disease. Radiographics 2009;29:553-65.

5 Rajbanshi BG, Burkhart HM, Schaff HV, et al. Surgical strategies for anomalous origin of coronary artery from pulmonary artery in adults. I Thorac Cardiovasc Surg 2014; 148:220-4

6 Sreenivasan VV, Jacobstein MD. Origin of the right coronary artery from the pulmonary trunk. Am I Cardiol 1992;69:1513-15.

7 Ten Kate GJ, Weustink AC, de Feyter PJ. Coronary artery anomalies detected by MSCT-coronary angiography in the adult. Neth Heart J 2008;16:369-75.

Copyright 2016 BMJ Publishing Group. All rights reserved. For permission to reuse any of this content visit

http://group.bmj.com/group/rights-licensing/permissions.

BMJ Case Report Fellows may re-use this article for personal use and teaching without any further permission.

Become a Fellow of BMJ Case Reports today and you can:

- Submit as many cases as you like

- Enjoy fast sympathetic peer review and rapid publication of accepted articles

- Access all the published articles

- Re-use any of the published material for personal use and teaching without further permission

For information on Institutional Fellowships contact consortiasales@bmjgroup.com

Visit casereports.bmj.com for more articles like this and to become a Fellow 